\title{
The Prevalence of Diabetes and Pre-Diabetes among the Dubai Population: Findings from Dubai Household Health Surveys, 2014 and 2017
}

\author{
Fatheya Alawadi $^{a}$ Mohamed Hassanein ${ }^{a}$ Eldaw Suliman ${ }^{c}$ Hamid Y. Hussain $^{c}$ \\ Heba Mamdouhc ${ }^{c}$ Gamal Ibrahim $^{c}$ Waleed Al Faisald ${ }^{d}$ Nahed Monsef ${ }^{b}$ \\ Mohammad Farghalye \\ a Department of Diabetes and Endocrinology, Dubai Hospital, Dubai Health Authority, Dubai, UAE; \\ ${ }^{b}$ Department of Strategy and Governance, Strategy and Corporate Development Sector, Dubai Health Authority, \\ Dubai, UAE; ' ${ }^{2}$ epartment of Data Analysis, Research and Studies, Strategy and Corporate Development Sector, \\ Dubai Health Authority, Dubai, UAE; ${ }^{d}$ Department of Public Health Protection, Dubai Health Authority, Dubai, UAE; \\ e Department of Health Economy and Insurance Policy, Dubai Health Authority, Dubai, UAE
}

\section{Keywords}

Diabetes · Pre-diabetes · Associated factors · Dubai

population - United Arab Emirates

\begin{abstract}
Background: Diabetes mellitus is a leading cause of morbidity and mortality worldwide, imposing a considerable burden on health systems and societies as it affects both individuals and their families and has a large impact on the economic and social development of a country. Objectives: The purpose of this study was to study the prevalence of diabetes and pre-diabetes among the Dubai population and associations with diabetes risk factors. Methodology: A cross-sectional Diabetes Household Survey was carried out in the Emirates of Dubai during 2017 as a complementary stage of the Dubai Household Survey, 2014, which was a randomly selected, multistage, stratified, cluster survey. The sampling technique was selected to assess the rates of undiagnosed diabetes as well as the rates of pre-diabetes through screening with $\mathrm{HbA} 1 \mathrm{c}$. The size of the 2017 survey
\end{abstract}

karger@karger.com www.karger.com/dde

Karger $\frac{1}{\%}$

GOPEN ACCESS
(C) 2020 The Author(s)

Published by S. Karger AG, Basel

This article is licensed under the Creative Commons AttributionNonCommercial-NoDerivatives 4.0 International License (CC BYNC-ND) (http://www.karger.com/Services/OpenAccessLicense). Usage and distribution for commercial purposes as well as any distribution of modified material requires written permission. sample was estimated at 300 individuals for Emirati and 300 for non-Emirati. An additional 200 individuals were added to address non-response cases. These were added to those who were identified as diabetics in the 2014 Household Health Survey and then weighted to give a representative sample for the Dubai population. Results: The study revealed that the prevalence of diabetes in Dubai among UAE nationals was $19 \%$, and it was $14.7 \%$ for expats. Consequently, the overall prevalence of diabetes in Dubai is $15.2 \%$. Undiagnosed diabetes was 10\% in UAE nationals and 10.9\% in expats. Pre-diabetes in UAE national males was lower than in females, although this pattern was not observed among expats. Younger age, normal weight, and exercise were associated with lower rates of diabetes and pre-diabetes in UAE nationals and expats. Hypertension was associated with higher rates of diabetes regardless of nationality. Conclusions: The study concluded that the prevalence of diabetes among the Dubai population is alarmingly high and that a large proportion of the population are not aware of their diagnosis. A higher prevalence of diabetes is associated with multiple factors, such as age, male gender, hyper- 
tension, higher BMI, lack of exercise, and lower level or no education, as well as a family history of diabetes mellitus. Many of these factors can be easily modified, which could lead to a decrease in the burden of the disease.

(C) 2020 The Author(s)

Published by S. Karger AG, Basel

\section{Introduction}

Diabetes mellitus is a leading cause of mortality and morbidity worldwide and it is imposing a considerable burden on health systems and societies as it affects both individuals and their families and has a large impact on the economic and social development of a country $[1,2]$. The burden of diabetes varies according to age, education, income, location, race/ethnicity, and other social determinants of health [1,3-5]. A greater burden is evident among adults with lower educational attainment and household income than among adults of higher socioeconomic status $[4,6]$. According to the International Diabetes Federation (IDF), currently more than 55 million adults aged 20-79 years have diabetes in the Middle East and North Africa region (MENA) [7]. The MENA region has the highest age-adjusted diabetes prevalence (12.5\%) of all the IDF regions [7]. Diabetes-attributable deaths account for $86.7 \%$ of all diabetes-related deaths in the region. According to the 2019 IDF statistics, the United Arab Emirates (UAE) has one of the world's highest prevalence rates of diabetes at $16.3 \%$ [7]. In addition, approximately $40.7 \%$ of adults (aged 20-79 years) with type 2 diabetes mellitus are unaware that they have the condition. The highest proportion of undiagnosed diabetes (59.7\%) occurs in the Africa region [7], while it reaches $44.7 \%$ in the MENA region [7]. Cross-sectional studies indicate that undiagnosed diabetes is associated with a higher prevalence of hypertension and obesity when compared with normal individuals [8]. Undiagnosed diabetes in a survey or screening setting can only be detected when an individual has a blood test [9].

Dubai is one of the fastest growing emirates in the UAE, with an estimated population of 3,355,900 in 2019. It has a dynamic and diversified economy, with a diverse and unique population structure in which male expats make up $69 \%$ of its population. Besides, $65 \%$ of the Dubai population are within the young age category (aged between 25 and 49 years) [10]. The rapid growth in the socioeconomic standard has provoked great changes in living standards and in the patterns of health and disease [11]. Traditional nutritional practices have changed and a sedentary lifestyle has infiltrated into the culture, which has resulted in many non-communicable diseases, including obesity and diabetes mellitus $[11,12]$. Over the last few years several studies have investigated the prevalence of diabetes and pre-diabetes in the UAE [13-16].

The government of Dubai continues to regularly monitor the health of the population. Therefore, the Dubai Health Authority, in collaboration with the Dubai Statistics Centre, conducted the Dubai Household Health Survey (DHHS) in 2014 and a supplementary survey in 2017 to assess the rate of undiagnosed diabetes as well as prediabetes. The DHHS covers a wide range of health and economic issues. Information about the prevalence of diabetes, pre-diabetes, and some of the diabetes-related risk factors among the sampled adult population of Dubai were obtained and are reported here.

\section{Data and Methods}

A cross-sectional household diabetes mellitus health survey was carried out in the Emirates of Dubai during 2017. Using a randomly selected, multistage, stratified, cluster survey sampling technique, enrolment of a subsample out of the original sample of DHHS 2014 was carried out. The DHHS consists of 4,800 families (divided into 2,000 Emirati and 2,000 non-Emirati families, as well as collective families). The 2017 survey was an extension stage (second stage) to the 2014 survey with further measures included to address undiagnosed diabetes and pre-diabetes within the Dubai population.

Those who indicated that they did not have diabetes during the 2014 survey were selected to assess the rates of undiagnosed diabetes and pre-diabetes through screening with HbAlc. The size of the 2017 survey sample was estimated at 300 individuals for Emirati and 300 for non-Emirati. An additional 200 individuals were added to address non-response cases. The supplementary sample was allocated in each stratum in proportion to the number of individuals who were not diagnosed according to the results of the basic survey in 2014. A systematic sampling method was adopted for drawing the supplementary sample of individuals in each stratum. Pre-diabetes was defined as $\mathrm{HbAlc} \geq 5.7$ to $\leq 6.4$. Diabetes was diagnosed with $\mathrm{HbA} 1 \mathrm{c} \geq 6.5$. HbA1c was analysed at the Dubai Health Authority central laboratory using the HbAlc measurement following the international standards of analysis. A total of 3,043 individuals responded to the initial extensive survey, and at the second phase 865 gave a blood sample. Clear inclusion and exclusion criteria were followed and strictly applied to avoid potential biases, and standard operational definitions of variables were adopted from internationally recognised standard practices. The design and methodology of the survey were adapted from those used in the World Bank's Living Standards Measurement Surveys (LSMS) and the World Health Organization's World Health Surveys (WHS). Around a hundred well-trained survey members visited families in their homes. All data were captured electronically using well-calibrated tablets. Data entry, coding, cleaning, weighing, and analysis was carried out using the SPSS program. Various descriptive and analytical statistical applications were used. The data were tested at a $95 \%$ level of significance and $p$ value $<0.05$. 
Fig. 1. Prevalence of diabetes mellitus (DM) and pre-DM in Dubai by nationality (DHHS 2014/17).

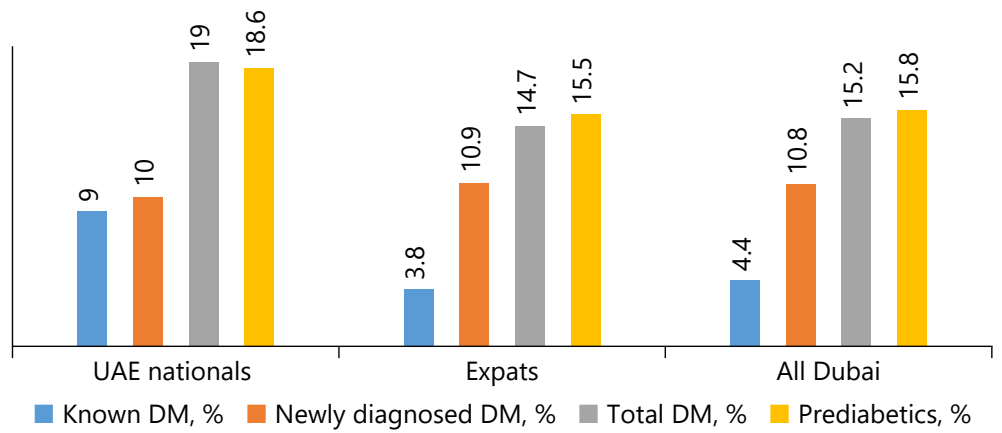

Known DM, \% Newly diagnosed DM, \% प Total DM, \% — Prediabetics, \%

Table 1. Prevalence of diabetes mellitus (DM) and pre-DM in Dubai by age and gender (DHHS 2014/17)

\begin{tabular}{|c|c|c|c|c|c|c|}
\hline & $\begin{array}{l}\text { UAE nationals } \\
\text { DM, \% }\end{array}$ & $\begin{array}{l}\text { UAE nationals } \\
\text { pre-DM, \% }\end{array}$ & $\begin{array}{l}\text { Expats } \\
\text { DM, \% }\end{array}$ & $\begin{array}{l}\text { Expats } \\
\text { pre-DM, \% }\end{array}$ & $\begin{array}{l}\text { All Dubai } \\
\text { DM, \% }\end{array}$ & $\begin{array}{l}\text { All Dubai } \\
\text { pre-DM, \% }\end{array}$ \\
\hline $20-29$ years & 0 & 12.6 & 2.3 & 4.7 & 2.0 & 5.6 \\
\hline $30-39$ years & 3.4 & 17.6 & 7.9 & 12.2 & 7.5 & 12.6 \\
\hline $40-49$ years & 21.6 & 20.5 & 19.2 & 25.7 & 19.4 & 25.3 \\
\hline $50-59$ years & 38.6 & 24.0 & 42.2 & 23.2 & 41.5 & 23.4 \\
\hline $60+$ years & 57.7 & 21.2 & 38.4 & 18.4 & 41.7 & 18.9 \\
\hline Males & 27.0 & 14.7 & 17.0 & 18.0 & 17.8 & 17.7 \\
\hline Females & 13.3 & 21.3 & 11.2 & 11.8 & 11.5 & 13.3 \\
\hline
\end{tabular}

\section{Results}

The results of the DHHS 2014 and the supplementary sample in 2017 show that the prevalence of diabetes in Dubai among UAE nationals is $19 \%$ and for expats it is $14.7 \%$. Consequently, the total prevalence of diabetes in Dubai is $15.2 \%$. Almost a similar percentage of pre-diabetes is also prevalent in Dubai (Fig. 1).

The data indicate a direct relationship of diabetes and pre-diabetes prevalence to age in both UAE nationals and expats, although expats in their 60s had a slightly lower prevalence of diabetes and pre-diabetes compared to those in their 50s (Table 1). Men had higher rates of diabetes among UAE nationals and expats. Pre-diabetes in male UAE nationals was lower than in females, although this trend was not sustained in expats (Table 1).

Similar to young age, normal weight and exercise were associated with lower rates of diabetes and pre-diabetes in UAE nationals and expats compared to those with a higher BMI or not exercising (Fig. 2). Smokers had a higher prevalence of diabetes compared to non-smokers in UAE nationals (38.6 vs. $18.1 \%$ ). This was not seen in expats, as the prevalence in smokers was $8.6 \%$ and in nonsmokers was $15.1 \%$. Hence, the prevalence of diabetes in
Dubai in smokers was $10.9 \%$ and in non-smokers was $15.4 \%$.

Hypertension was associated with higher rates of diabetes regardless of nationality, as shown in Figure 3. However, this was not consistent in pre-diabetes as the rate of pre-diabetes in UAE nationals without hypertension was $14.3 \%$ and in those diagnosed with hypertension was $15.7 \%$. In expats, the rate of pre-diabetes in those without hypertension was $18.3 \%$ and in those with hypertension was $15.9 \%$. Consequently, the overall rate of prediabetes in those without hypertension was $17.9 \%$ and in those with hypertension was $15.9 \%$.

The unadjusted data of marital status indicate that being single was associated with lower rates of diabetes and pre-diabetes in both Dubai UAE nationals as well as expats. Being separated, divorced, or widowed was associated with the highest rate of diabetes in Dubai UAE nationals; however, this was not seen in Dubai expats (Table 2). There was also a discrepancy in the rates of pre-diabetes between Dubai UAE nationals and expats in pre-diabetes prevalence rates according to marital status where being married had the highest rate in UAE nationals, while in expats being separated, divorced, or widowed was associated with the highest rate (Table 2).
Alawadi et al. 
Fig. 2. Impact of BMI and exercise on the prevalence of diabetes mellitus (DM) and pre-DM (DHHS 2014/17).
Fig. 3. Prevalence of diabetes mellitus (DM) according to diagnosis of hypertension (DHHS 2014/17).
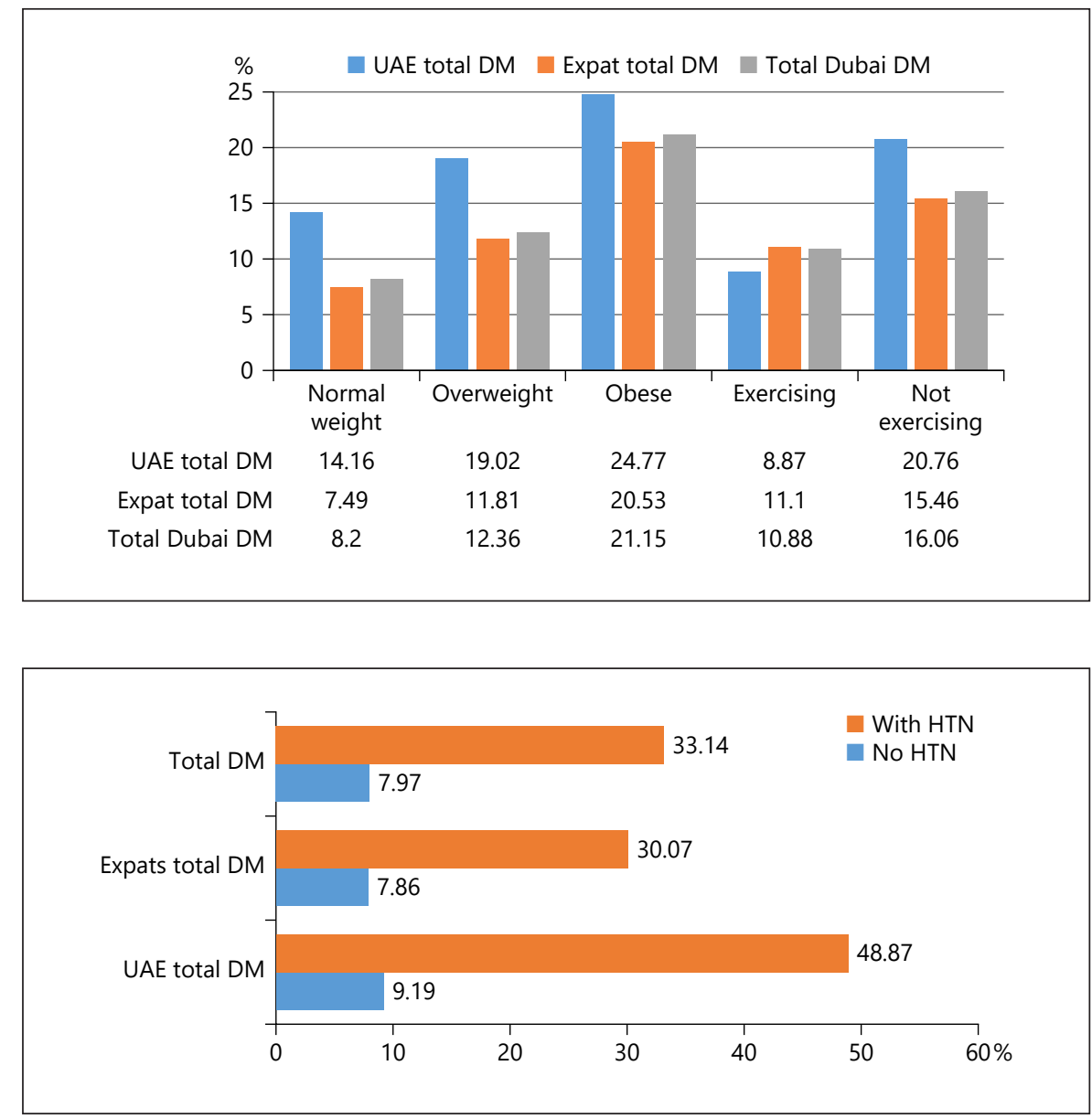

A family history of diabetes was associated with the prevalence of diabetes in the DHHS 2014/17 data. The overall diabetes data prevalence in Dubai in those without a family history of the condition was $13.9 \%$, while for those with a family history of diabetes it was $52.7 \%$. This association was reversed in pre-diabetes (Table 2).

The DHHS 2014/17 data indicate that the rate of undiagnosed diabetes was almost equal to those known to have diabetes in Dubai UAE nationals, and was much higher in Dubai expats. Consequently, the overall Dubai known diabetes rate was $4.4 \%$, and for undiagnosed diabetes it was $10.8 \%$ (Table 3 ). In general, there was much more undiagnosed diabetes in Dubai expats compared to Dubai UAE nationals, with an exception being among smokers. There was no difference between diagnosed and undiagnosed diabetes in Dubai UAE nationals in those who are married. Table 3 details all the DHHS 2014/17 parameters according to previously known diabetes or undiagnosed diabetes. It is important to mention that in some parameters there was some missing data.

Prevalence of Diabetes and Pre-Diabetes among the Dubai Population

\section{Discussion}

The present study is based on the first DHHS results that include blood testing for the detection of undiagnosed and pre-diabetes, and hence provides a comprehensive picture about the glycaemic status of Dubai residents, whether Emiratis or expats. While the data from Dubai cannot be generalised to the whole of the UAE, it gives a very good idea about the approximate prevalence of diabetes in the UAE, and seems to be in line with what is recorded in the 2019 IDF Atlas regarding the prevalence of diabetes for the UAE [7]. They estimated the ageadjusted prevalence of diabetes in the UAE to be $16.3 \%$, while the current survey indicates that the overall prevalence in Dubai is $15.2 \%$. Indeed, the prevalence of diabetes in Dubai Emiratis seen in this DHHS more or less matches what has been revealed by other recent UAE studies as well as data from other Gulf countries [11-13].

The DHHS results showed that the prevalence of diabetes among UAE nationals was $19 \%$, while pre-diabetes 
Table 2. Prevalence of diabetes mellitus (DM) by marital status and family history of DM (DHHS 2014/17)

\begin{tabular}{|c|c|c|c|c|c|c|}
\hline & \multicolumn{2}{|c|}{ UAE nationals, \% } & \multicolumn{2}{|l|}{ Expats, \% } & \multicolumn{2}{|c|}{ All Dubai, \% } \\
\hline & total DM & pre-DM & total DM & pre-DM & total DM & pre-DM \\
\hline Single & 4.4 & 9.0 & 2.5 & 2.7 & 2.8 & 3.7 \\
\hline Married & 20.8 & 23.0 & 16.6 & 16.9 & 17.0 & 17.5 \\
\hline Separated/divorced/widowed & 32.1 & 9.4 & 10.1 & 71.3 & 25.2 & 28.9 \\
\hline No family history of DM & 14.6 & 18.4 & 13.8 & 15.9 & 13.9 & 16.1 \\
\hline Family history of DM & 53.9 & 20.1 & 52.0 & $0^{\mathrm{a}}$ & 52.7 & 7.3 \\
\hline
\end{tabular}

${ }^{a}$ Missing data.

Table 3. Prevalence of diabetes mellitus (DM) according to known or undiagnosed DM (DHHS 2014/17)

\begin{tabular}{|c|c|c|c|c|c|c|}
\hline & \multicolumn{3}{|c|}{ Known DM, \% } & \multicolumn{3}{|c|}{ Undiagnosed DM, \% } \\
\hline & $\begin{array}{l}\text { UAE } \\
\text { nationals }\end{array}$ & Expats & all Dubai & $\begin{array}{l}\text { UAE } \\
\text { nationals }\end{array}$ & Expats & all Dubai \\
\hline Total & 9.0 & 3.8 & 4.4 & 10.0 & 10.9 & 10.8 \\
\hline \multicolumn{7}{|l|}{ Age group } \\
\hline $18-29$ years & 0 & 0 & 0 & 0 & 2.3 & 2.0 \\
\hline $30-39$ years & 1.5 & 2.1 & 2.1 & 1.9 & 5.8 & 5.5 \\
\hline $40-49$ years & 8.8 & 4.6 & 4.9 & 12.9 & 14.6 & 14.5 \\
\hline $50-59$ years & 14.2 & 11.6 & 12.1 & 24.4 & 31.0 & 29.5 \\
\hline $60+$ years & 42.1 & 13.3 & 18.1 & 15.7 & 25.2 & 23.6 \\
\hline \multicolumn{7}{|l|}{ Gender } \\
\hline Male & 11.7 & 4.8 & 5.3 & 15.3 & 12.3 & 12.5 \\
\hline Female & 7.2 & 2.4 & 3.2 & 6.1 & 8.8 & 8.4 \\
\hline \multicolumn{7}{|l|}{ BMI } \\
\hline Normal weight & 5.5 & 2.7 & 3.0 & 8.7 & 4.8 & 5.2 \\
\hline Overweight & 8.6 & 3.3 & 3.7 & 10.4 & 8.5 & 8.7 \\
\hline Obese & 11.9 & 7.2 & 7.9 & 12.9 & 13.4 & 13.3 \\
\hline \multicolumn{7}{|l|}{ Exercise } \\
\hline Exercising & 7.7 & 2.4 & 3.0 & 1.2 & 8.7 & 7.9 \\
\hline Not exercising & 9.3 & 4.1 & 4.7 & 11.5 & 11.3 & 11.3 \\
\hline \multicolumn{7}{|l|}{ Smoking } \\
\hline Yes & 32.5 & 5.7 & 7.84 & 6.06 & 2.85 & 3.1 \\
\hline No & 8.0 & 3.7 & 4.2 & 10.1 & 11.4 & 11.3 \\
\hline \multicolumn{7}{|l|}{ Family history of DM } \\
\hline No & 5.9 & 3.5 & 3.8 & 8.7 & 10.2 & 10.1 \\
\hline Yes & 34.1 & 16.1 & 22.7 & 19.8 & 35.9 & 30.0 \\
\hline \multicolumn{7}{|l|}{ Hypertension } \\
\hline No & 5.1 & 2.3 & 2.6 & 4.1 & 5.6 & 5.4 \\
\hline YES & 23.3 & 11.1 & 13.1 & 25.6 & 19.0 & 20.1 \\
\hline \multicolumn{7}{|l|}{ Marital status } \\
\hline Single & 0.6 & 0.5 & 0.9 & 3.8 & 2.1 & 2.3 \\
\hline Married & 10.4 & 4.3 & 4.8 & 10.4 & 12.3 & 12.1 \\
\hline Separated/divorced/widowed & 15.0 & 10.1 & 13.5 & 17.1 & $0^{\mathrm{a}}$ & 11.7 \\
\hline \multicolumn{7}{|l|}{ Level of education } \\
\hline No education & 18.6 & 2.9 & 7.6 & 15.4 & 6.5 & 9.2 \\
\hline Primary & 13.7 & 4.7 & 6.3 & 22.4 & 17.4 & 18.2 \\
\hline Secondary & 5.7 & 4.1 & 4.3 & 5.6 & 17.6 & 15.7 \\
\hline University or higher & 3.6 & 3.7 & 3.7 & 3.6 & 7.8 & 7.5 \\
\hline
\end{tabular}

a Missing data. 
among UAE nationals was $18.6 \%$. This finding seems to be more or less similar to the findings shown by a study in Saudi Arabia (pre-diabetes was $9.0 \%$ and diabetes was 12.1\%) [17].

The DHHS revealed that the highest prevalence of diabetes and pre-diabetes was among UAE nationals. The age groups 50-59 and 60+ years has the highest prevalence, which is similar to the results of several studies in Saudi Arabia, Kuwait, and Oman [17-19].

Various risk factors are associated with higher rates of diabetes. The results of the current DHHS show that the risk factors of smoking, hypertension, obesity, and physical inactivity are all associated with a higher prevalence of diabetes and pre-diabetes among UAE nationals as well as expats. This matches what was previously observed in other studies in Saudi Arabia and Kuwait [20,21]. Such findings can be explained by metabolic changes predisposed by long-term exposure to risk factors.

Male gender was associated with a higher prevalence of diabetes compared to females, which is in line with the ADA (American Diabetes Association) risk calculation that considers being male as a risk factor for developing diabetes [22]. A family history in this study was associated with a higher prevalence of diabetes and pre-diabetes among both UAE nationals and expats. A higher prevalence of diabetes was detected among low educational status cohorts compared to those with a high level of education, and the same is applicable regarding marital status, which revealed a higher prevalence among separated groups compared to other groups. It is important to note that this subanalysis is not age adjusted and could potentially be age related. In general, all of these associations are in coherence with the findings of other existing studies in the UAE [23].

Addressing the question of undiagnosed diabetes and pre-diabetes was essential for the DHHS as the original data depended only on known diabetes and, consequently, the prevalence of diabetes was low in comparison with other studies that utilised a screening test [14-16]. Indeed, the IDF recognises the fact that, globally, there is a large proportion of people with diabetes who are unaware of their condition [7]. There are multiple tests recognised for screening in various studies and diabetes guidelines. $\mathrm{HbA} 1 \mathrm{c}$ is recognised by the ADA as a diagnostic tool for diabetes and pre-diabetes [22]. In DHHS 2014/17 this was the preferred test for multiple logistics matters, including the ability to complete the survey without needing to ask the individuals to fast and/or have another blood test later, which could have compromised rates of completion of the survey. The affordability of HbA1c is usually an inhibiting

Prevalence of Diabetes and Pre-Diabetes

among the Dubai Population factor when utilised as the screening test; however, we are grateful that the cost of the test was included in the survey supplementary budget from Dubai Health Authority.

Table 3 shows details of the variable parameters of undiagnosed versus diagnosed diabetes. Undiagnosed diabetes in this survey was present in both UAE nationals and expats at a rate of about $10 \%$. The much higher level of undiagnosed to diagnosed diabetes among expats could be related to the reduced accessibility to healthcare services that some expats have.

The study shows that males have a higher prevalence of both diabetes and undiagnosed diabetes in both UAE nationals and expats. Female expats also had higher rates of undiagnosed diabetes, while the rate of undiagnosed diabetes was lower in female UAE nationals within Dubai, which could be attributed to better healthcare seeking among them as well as the routine practice of premarital health checks.

The data from our study also show that rates of undiagnosed diabetes were high in the subgroups where the diabetes prevalence is not expected to be high. This was noted in those with normal BMI, non-smokers, those with no family history of diabetes, as well as normotensive expats. This is probably related to more robust screening of those who appear to have a higher risk of developing diabetes, such as those with a higher BMI, smokers, or hypertensive individuals. Finally, having primary education was associated with higher rates of undiagnosed diabetes in Dubai UAE nationals. This was not seen in those with no education of the same group. The explanation for such variation is not clear.

\section{Study Limitations}

The study contained some limitations, such as missing data, which may have led to data inadequacy and insufficiency to make a powerful subgroup analysis. The complex stratification of the data is another limitation, which could have led to further restrictions in applying multivariate analyses.

\section{Conclusions}

The prevalence of diabetes and pre-diabetes among the Dubai population in the study period was remarkably high. Furthermore, a large proportion of people with diabetes or pre-diabetes are not aware of their diagnosis. The results indicate that the prevalence of diabetes and pre-diabetes is associated with multiple risk factors, such as increasing age, male gender, hypertension, high BMI, 
and low or no education, as well as a positive family history for diabetes. Many of these risk factors can be modified to reduce the burden of diabetes in the coming years. All efforts are required to provide robust screening of those at risk, and strategies for prevention of diabetes are needed to halt the progression of this important health problem.

\section{Acknowledgements}

The research team would like to express their appreciation and gratitude to the team of Dubai Statistics Centre for their significant contribution to the Household Health Survey. We also extend our thanks to Dr. H. AlSamt, Pathology and Genetics Department, HQ, and Ms. H.B. Natouf from the Pathology Section of PHC, Dubai Health Authority, for their significant support throughout the survey.

\section{Statement of Ethics}

Ethical standards were adhered to throughout this study.

\section{Conflict of Interest Statement}

All authors declare that they have no conflicts of interest.

\section{Funding Sources}

There are no funding sources to declare.

\section{Author Contributions}

All authors contributed to the conception of the survey data analysis and manuscript writing.

\section{References}

1 Shariful Islam SM, Lechner A, Ferrari U, Froeschl G, Niessen LW, Seissler J, et al. Social and economic impact of diabetics in Bangladesh: protocol for a case-control study. BMC Public Health. 2013 Dec;13(1):1217.

2 Afroz A, Alramadan MJ, Hossain MN, Romero L, Alam K, Magliano DJ, et al. Cost-of-illness of type 2 diabetes mellitus in low and lower-middle income countries: a systematic review. BMC Health Serv Res. 2018 Dec 18(1):972.

3 Deputy NP, Kim SY, Conrey EJ, Bullard KM. Prevalence and changes in pre-existing diabetes and gestational diabetes among women who had a live birth-united States, 2012 2016. MMWR Morb Mortal Wkly Rep. 2018 Nov;67(43):1201-7.

4 Beckles GL, Chou CF. Disparities in the prevalence of diagnosed diabetes - United States, 1999-2002 and 2011-2014. MMWR Morb Mortal Wkly Rep. 2016 Nov;65(45): 1265-9.

5 Menke A, Casagrande S, Geiss L, Cowie CC. Prevalence of and trends in diabetes among adults in the United States, 1988-2012. JAMA. 2015 Sep;314(10):1021-9.

6 Centers for Disease Control and Prevention. National Diabetes Statistics Report, 2017. Atlanta: Department of Health and Human Services; 2017.

7 International Diabetes Federation. IDF Diabetes Atlas. 9th ed. Brussels: International $\mathrm{Di}-$ abetes Federation; 2020. pp. 7-44.

8 Harris MI. Undiagnosed NIDDM: clinical and public health issues. Diabetes Care. 1993 Apr;16(4):642-52.
9 Young TK, Mustard CA. Undiagnosed diabetes: does it matter? CMAJ. 2001 Jan;164(1): 24-8.

10 Dubai Statistics Center. Population by gender - Emirate of Dubai, 2019 [accessed April 15, 2020]. Available from: https://www.dsc.gov. ae/en-us/Themes/Pages/Population-and-Vital-Statistics.aspx?Theme $=42$.

11 Musaiger AO. Diabetes mellitus in Bahrain: an overview. Diabet Med. 1992 Jul;9(6):574-8.

12 Al-Daghri NM, Al-Attas OS, Alokail MS, Alkharfy KM, Yousef M, Sabico SL, et al. Diabetes mellitus type 2 and other chronic noncommunicable diseases in the central region, Saudi Arabia (Riyadh cohort 2): a decade of an epidemic. BMC Med. 2011 Jun;9(1):76.

13 Sulaiman N, Mahmoud I, Hussein A, Elbadawi S, Abusnana S, Zimmet P, et al. Diabetes risk score in the United Arab Emirates: a screening tool for the early detection of type 2 diabetes mellitus. BMJ Open Diabetes Res Care. 2018;6(1):e000489.

14 Sulaiman N, Albadawi S, Abusnana S, Mairghani M, Hussein A, Al Awadi F, et al. High prevalence of diabetes among migrants in the United Arab Emirates using a cross-sectional survey. Sci Rep. 2018;8(1):6862.

15 Sulaiman N, Elbadawi S, Hussein A, Abusnana S, Madani A, Mairghani A, et al. Prevalence of overweight and obesity in United Arab Emirates Expatriates: the UAE National Diabetes and Lifestyle Study. Diabetol Metab Syndr. 2017 Nov;9:88.

16 Sulaiman N, Albadawi S, Abusnana S, Fikri M, Madani A, Mairghani M, et al. Novel approach to systematic random sampling in population surveys: Lessons from the United Arab Emirates National Diabetes Study (UAEDIAB). J Diabetes. 2015;7:642-8.

17 Bahijri SM, Jambi HA, Al Raddadi RM, Ferns G, Tuomilehto J. The prevalence of diabetes and prediabetes in the adult population of Jeddah, Saudi Arabia - a community-based survey. PLoS One. 2016 Apr;11(4):e0152559.

18 Alkandari A, Longenecker JC, Barengo NC, Alkhatib A, Weiderpass E, Al-Wotayan R, et al. The prevalence of pre-diabetes and diabetes in the Kuwaiti adult population in 2014. Diabetes Res Clin Pract. 2018 Oct;144:21323.

19 Al-Lawati JA, Al Riyami AM, Mohammed AJ Jousilahti P. Increasing prevalence of diabetes mellitus in Oman. Diabet Med. 2002 Nov; 19(11):954-7.

20 Khlid Al A. Abbas Al M, Nisha S. Risk factors associated with diabetes mellitus in a Saudi community: a cross-sectional study. Prim Health Care. 2017;7:270.

21 Alarouj M, Bennakhi A, Alnesef Y, Sharifi M Elkum N. Diabetes and associated cardiovascular risk factors in the State of Kuwait: the first national survey. Int J Clin Pract. 2013 Jan; 67(1):89-96.

22 ADA. Standards of medical care in diabetes - 2020. vol. 43, suppl. 1. https://care.diabetesjournals.org/content/43/Supplement_1.

23 Hamoudi R, Sharif-Askari NS, Sharif-Askari FS, Abusnana S, Aljaibeji H, Taneera J, et al. Prediabetes and diabetes prevalence and risk factors comparison between ethnic groups in the United Arab Emirates. Sci Rep. 2019 Nov; 9(1):17437. 